\title{
Flowering Dates of Trees along Main British Railway Routes.
}

\section{By J. Edmund Clark.}

A FEW months ago the Editor of Nature sent me, as joint editor of the Phenological Reports published by the Royal Meteorological Society, an interesting problem. $\mathrm{He}$ said:"It has been pointed out on several occasions that in travelling from the West of England (Devon and Cornwall) to London, fruit trees are usually seen to be much more forward as regards flowering nearer London than in the West." I was therefore asked whether I had, among the " phenological observations, records of such flowering dates arranged according to longitude so as to determine whether fruit trees do, normally, bloom earlier near London than far away, and whether this is true also in passing from London to the East."

Our thirty years' records give no basis for a direct reply, since of set purpose garden flowers and fruits were excluded by the late Edward Mawley from the thirteen selected blossomings. These begin with the hazel (mean for the British Isles, February 13) and close with the ivy (October 2). The many varieties of most of our fruit trees is the obvious ground for their exclusion.

It seemed, however, worth attacking the problem indirectly, even though at first the supposed earliness appeared to be improbable. The four fruit-time plants in our list, blackthorn, garlick hedge-mustard, horse chestnut, and hawthorn, average two and a half days earlier in England, S.W., than in England, S.E. and E., in our thirty years' means.

The basis for investigation required:-

(I) Sufficient stations. For the first time in the thirty years 1920 supplies these, thirty-five being available. ${ }^{1}$

(2) The blackthorn gives us the opening, the other two trees the closing, stages of fruit flowering.

(3) Unfortunately 1920 was abnormally early, and therefore prolonged. This is shown by the following table, giving the days early compared with the mean :-

$\begin{array}{lcccrr}\quad & & \text { S.W. } & \text { S.E. } & \text { E. } \\ \text { Blackthorn, early } & \ldots & \text { days } & 30 & 24 & 20 \\ \text { Chestnut and may, early } & \ldots & , " & \text { IO } \frac{1}{2} & \text { I8 } & \text { I2 } \\ \text { Prolongation, fruit fowering.. } & \text { ", } & \text { I } 9 \frac{1}{2} & 6 & 8\end{array}$

The possible results on relative conditions may well be serious, especially as to insolation. Obviously any such effect would be most marked in England, S.W.

(4) The isophenes (lines of equal flowering date) have for the first time been tested for agreement with Prof. Hopkins's Bioclimatic Law, recently formulated and found to hold well in the United States. Starting from a given station, this postulates a retardation of four days in flowering for every additional $400 \mathrm{ft}$. of altitude, $\mathrm{I}^{\circ}$ of latitude

I See our Phenological Report to the Royal Meteorological Society for I920 (Part 3), 1921.

NO. 2729 , VOL. IO9] and $5^{\circ}$ eastward in longitude ${ }^{2}$; the reverse for negative values. Both he and we have found it fairly trustworthy for the British Isles, and he for Western Europe. This has enabled me to reduce the records to sea-level, so as to see whether there is any factor other than the higher elevations along most of the way until London is approached.

(5) Since it is most difficult faithfully to record the average date of first flowering, after taking the mean of the three trees for each of the thirtyfive stations available (those within twelve to fifteen miles of the selected railway routes), the mean of two or more adjacent stations was taken, so far as possible. In this way we have fifteen sets of records available.

(6) Unfortunately the L.S.W.R. route from Exeter to London was useless, no records being available between Exeter and Fleet.

The results are shown in the following table:-

Mean Flowering Date, Sloe, Chesinut, May, Ig20.

$$
\text { Stations }
$$

I. Penzance, Camborne, Falmouth $\quad \ldots \quad$ April 8

II. Polperro (2), Duloe

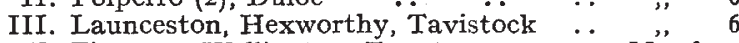

IV. Tiverton, Wellington, Taunton .. . . March 30

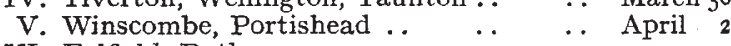

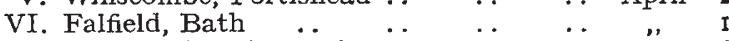

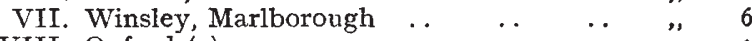

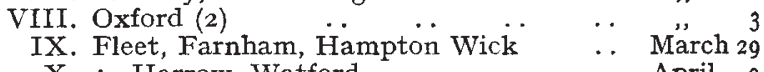

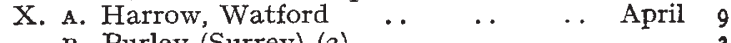

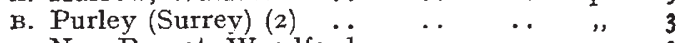

XI. A. New Barnet, Woodford $\quad$. $\quad$. , , 2 B. Hayes and Bromley (Kent) ... .. March 28

XIr. A. Maldon, Hatfield Peverel, Lexden .. April 5

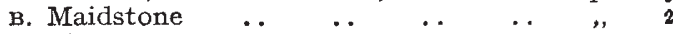

I. to IX. closely follow the G.W.R. from Penzance to London; X.A, XI.A, and XII.A continue on north of the Thames Estuary to Colchester; X.B, XI.B, and XII.B south of it to Maidstone.

Of I. to IX. the earliest date is just before reaching London; the latest in the foot of Cornwall. East Devon and Somerset fall little behind London; whilst East Cornwall, West Devon, and North Wilts are nearly as late as I. Hopkins's latitude and longitude corrections, however, intensify the contrast, the date relative to London working out to April 18 .

Eastwards from London flowering dates north of the Thames are retarded, but to the south scarcely at all, Hayes and Bromley (Kent)March 28-having the earliest date of all.

Before considering possible explanations, two cautions must be reiterated. The transfer here of Hopkins's Law values is still only tentative, and the dates of observation may well be subject to a margin of error of a day or two. Making full allowance for these, we may still believe that general observation is verified, the more so that,

As a fact, the law is more general, governing all seasonal plank phenomena; the regressive phases, of course require the reverse of the above statement. 
as noted already, the earliness of 1920 was most strongly marked in England, S.W. We therefore conclude that London is at least a week earlier than Penzance in its fruit flowering; also that, at any rate in an early season, while further advance eastward south of the Thames estuary results in little change, there is a decided retardation on the opposite bank as one proceeds in a north-easterly direction. It is difficult to account for the Harrow-Watford delay. Further on the cooling influence of the North Sea and of east winds may come into play. The isophenes cut the East Coast, the direction varying N.E. to N. East-wind exposure may partly account for the retardation at Purley (Surrey) and on the Wiltshire downs. It is not easy offhand to suggest the reason affecting the extreme southwest, which must be largely influenced by ocean conditions. One would expect the fruit-flowering season to share in the relative earliness shown by the means of all twelve flowers (omitting ivy), ranging from February 6 to July i5. One may, however, note that, for the first six months, isotherms and isohels taken together slightly favour the London area, but in April the reverse was the case.

The East Devon and Somerset earliness was fully expected. Each year the isotherms show a remarkable uprush of warmth along the Severn sea and watershed and a corresponding lie of the isophenes. In 1920 the isotherm bulge reached the borders of Yorkshire.

Having thus considered the query raised, an extension of the subject may be of interest along two other lines through London, which I have worked out for the sake of comparison. These are: (I) The L.B.S.C.R. from the Isle of Wight and on by the East Coast route to Edinburgh and Ross-shire; (2) from East Sussex and on by the West Coast route to the Glasgow district. Round London much the same stations come in along all three lines. The comparison is best made by placing the two series side by side, arranged roughly by latitude $\left(5 \frac{3}{4}^{\circ}\right.$ to $\left.57^{\frac{3}{4}}{ }^{\circ}\right)$. The numbers in brackets show the number of stations in each group.
As one expects, both series give a decided delay with latitude and longitude. Hopkins's corrections for these from London to Ardross Castle $\left(+6 \frac{1}{4}^{\circ}\right.$ and $+4^{\circ}$ ) give the relative date for the latter April 28 . For Glasgow $\left(4^{\frac{1}{2}}{ }^{\circ}\right.$ and $\left.4^{\circ}\right)$ we get April 26, the value round the Firth of Forth $\left(4 \frac{1}{2}^{\circ}, 3^{\circ}\right)$ being April I 2 .

Either Hopkins's Law needs modification for the period in question, more than is indicated by the whole period, or there are special influences at work, such as oceanic effects, prevalence of east winds, and propinquity of hill and mountain masses. Nor need these be mutually exclusive.

To investigate them more complete data are required. For instance, we hope shortly to have mean values for a considerable number of stations over the thirty years of our records. The most obvious effect at present is perhaps the retardation for the spring period in question, due to high elevation, and even more the propinquity of hill and mountain masses. Is this due to the lag effect of their winter cooling? Snow would still be lying on the Welsh mountains in blackthorn days.

May I, in conclusion, direct the attention of readers of NATURE to the need for yet further observers, especially in the districts indicated by the lacunæ in the tables and the fact that the L.S.W.R. from Exeter could not be used? Either my colleague, Mr. H. B. Adames (33 Holcombe Road, Ilford), or myself (Asgarth, Purley) will gladly give further information, or observing forms can be had direct from the Assistant Secretary of the Royal Meteorological Society, Cromwell Road, S.W.7. When we see the prominent position elsewhere, especially in the United States, taken by phenological work in its bearing on horticulture and agriculture, we realise the need in this country for greater unification in and concentration on its investigations.

Since the above was in print Prof. Hopkins has sent us the typed copy of an unpublished exhaustive discussion of the bioclimatic association

Mean Flowering Date, Sloe, Chestnut, May, I920.

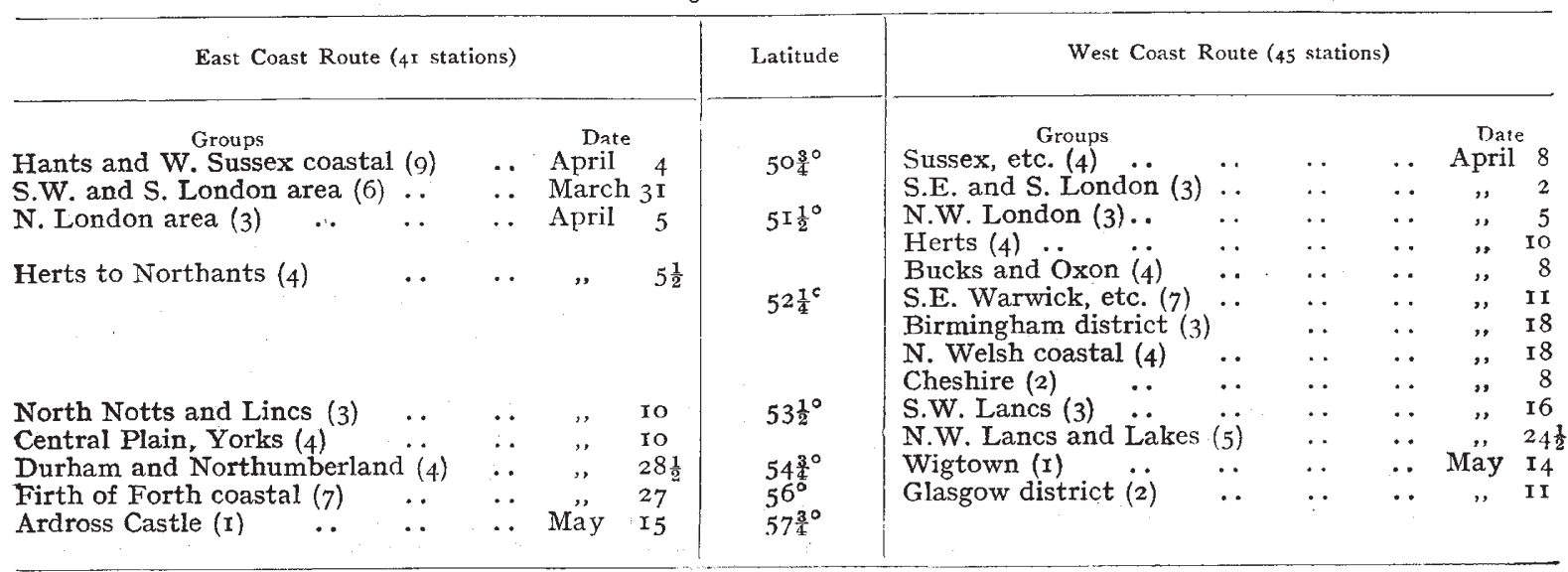


between North America and Eurasia. He has correlated the two continents by using: for the four years: I916-1919 the flowering date of hawthorn, Crataegus oxyacantha, at our station of Tenbury, Worcestershire, with the date for the leafing of the hickory, Carya alba, at his own station of Kanawha: Farm, West.Virginia, adopted as base for intercontinental correlations. Working from the latter, he found the closest agreement with our 25-year mean; less divergent, he considers, than errors of observation.

In order to test his calculation, and again starting from his U.S.A. base, Prof. Hopkins morked out the theoretical means for the eleven Rritish meteorological districts. Scotland N. and Ireland $\mathrm{S}$. differed by I I days, Scotland W. by 5. These three districts are our worst, from paucity of observers: But this year we have completed (see Q.J. Ray. Met. Soc. for October last) the 30-year mean values, worked out entirely afresh and carefully weighted for defective records. Compared with these far more trustworthy figures, the discrepancies found by Prof. Hopkins are reduced to three, one, and four days respectively, the eight other districts also giving closer agreements. Thus, though as yet unknown to Prof. Hopkins, his results are well confirmed.

The success obtained seems to imply that from absolutely trustworthy phenological records of seasonal changes for a single station in the northern hemisphere for one single plant, the whole seasonal phenology for any other plant or crop can be postulated for any other spot in North America; Europe or Asia. The publication of this paper should be an important step in this branch of applied science.

\section{O.bituary.}

Dr. James Francis Bottomley.

$\mathrm{B}^{\mathrm{y}}$ the death of Dr. Frank Bottomley-due to pneumonia following influenza-which occurred on January I6 at the early age of fortyseven, the country has lost the services of a chemist, physicist, technician, negotiator, and manager of men of quite exceptional ability and integrity.

Heredity and environment conspired to make Dr. Bottomley a man of science. His great-grandfather was Dr. James Thomson, professor of mathematics in Glasgow University; his great-uncles were Lord Kelvin and James Thomson, F.R.S., professor of engineering in Queen's College, Belfast, and Glasgow University; while his father was the present: Dr. James Thomson Bottomley, F.R.S., of Glasgow University. His mother died when he was three years old, but five years later his father married the widowed sister of Lord Kelvin, and between the boy and his stepmother there arose an attachment which deeply influenced his character.

From eight to thirteen years of age Dr. Bottomley was educated at Bloxham, near Banbury, where he became interested in science, but his school career was cut short by influenza in the epidemic of 1888 . After a long period of convalescence he entered the University of Glasgow-first as a non-matriculated, and afterwards as a matriculated, student-under Prof. Ferguson, Lord Kelvin, and Prof. Jack. In his second year he was laid up with scarlet fever and so lost the chance of taking his degree. In r894, at nineteen years of age, he went to Germany, and, after about six months with a German family, entered the University of Heidelberg. Here he came under the influence of Victor Meyer and Prof. Gattermann, and also studied physics under Prof. Quincke, mathematics under Prof. Konigsberg, and mineralogy under Prof. Rosenbusch. In 1897 he obtained the Ph.D. degree "multa cum laude," and returned to Glasgow, where he entered the university chemical laboratory and physical laboratory.

NO. 2729 , VOL. IO9]
In r 898 Dr. Bottomley was awarded a research studentship for three years, the first of which he spent at Glasgow, the second at Owens College, Manchester--where he was elected research student and afterwards research fellow under Prof. W. H. Perkin-and the third at University College, London, under Sir William Ramsay. Here, according to Ramsay, he showed "manipulative skill of the highest order," and proved himself " an accomplished chemist and a courteous gentleman." In I $90 \mathrm{I}$ he joined the standardising laboratory of Kelvin and James White, and a year later was associated with the Newcastle-upon-Tyne Electric Supply Co., and became also chemical expert to the firm of Merz and McLellan (then C. H. Merz), consulting electrical engineers.

In 1902 Dr. Bottomley began his great work on silica fusion on a commercial scale by means of the electric furnace. The research was carried out at Wallsend, and by skilful and systematic experiment he eventually solved the many technical difficulties which had defeated prior experimenters, and, as managing director of the Thermal Syndicate, Ltd., became responsible for the commercial, as well as for the scientific and technical, development of the work. In I910 his company received the gold medal for its exhibit of fused silica ware (vitreosil) at the Brussels Exhibition, and the gold medal for a similar exhibit at Turin in rom I.

In 1914 the process, which was by this time well established, afforded almost the only material then manufactured in the United Kingdom in which acids could be concentrated for the manufacture of explosives. The output of the works was increased tenfold, and the burden of designing and supervising the necessary extensions and of the technical management fell, for the most part, on Dr. Bottomley. So successful was he as a manager that throughout the war and up to the time of his death the works were entirely free from labour troubles. After the armistice he was mainly occupied in 